\title{
Autosomal dominant myoglobinuria
}

INSERM

\section{Source}

INSERM. (1999). Orphanet: an online rare disease and orphan drug data base. Autosomal dominant myoglobinuria. ORPHA:99846

Autosomal dominant myoglobinuria is a rare metabolic myopathy characterized by episodic myalgia with myog lobinuria which is induced by fever, viral or bacterial infection, prolonged exercise or alcohol abuse, and could, on occasion, lead to acute renal failure. Between episodes, patients may be asymptomatic or could present elevated creatine kinase levels and mild muscle weakness. There have been no further descriptions in the literature since 1997. 